\title{
Syndrome of valvular pulmonary stenosis and valvular aortic stenosis with atrial septal defect
}

\author{
RICHARD J. SHEMIN, KENNETH M. KENT, AND WILLIAM C. ROBERTS \\ From the Surgery, Cardiology, and Pathology Branches, National Heart, Lung, and Blood Institute, \\ National Institutes of Health, Bethesda, Maryland 20014, USA
}

SUMMARY Clinical and morphological findings are described in 2 adults with combined valvular pulmonary and aortic stenosis with atrial septal defect, an extremely rare combination of lesions. The direction of the shunt via the atrial septal defect in this combination appears to be dependent on the relative degree of outflow obstruction on the right side compared with the left side of the heart. In 1 patient the degree of obstruction at the pulmonary valve was nearly three times that at the aortic valve and, therefore, the shunt was right to left and the patient was severely cyanotic. In the other patient, the degree of obstruction at the pulmonary valve was slightly less than that at the aortic valve and, therefore, the shunt was entirely left to right and the patient was acyanotic. Diagnosis of an associated obstructive lesion on the left side of the heart in a patient with an obstructive lesion on the right side of the heart is essential because operative relief of the right-sided obstruction without relief of the left-sided obstruction may lead to rapid, fatal pulmonary congestion.

Isolated pulmonary valve stenosis, with or without patent foramen ovale, is fairly common. Isolated aortic valve stenosis, in contrast, is far more common but associated patency of the foramen ovale is infrequent (Roberts, 1970). Though both as isolated lesions are common, combined pulmonary and aortic valve stenosis in the same patient is extremely rare with or without associated atrial septal defect. This report describes clinical and morphological observations in 2 adults with combined valvular pulmonary and aortic stenosis associated with atrial septal defect, and points out useful findings which should call attention to this unusual combination of lesions.

\section{Case reports}

\section{CASE 1}

A 33-year-old man was noted to have a praecordial murmur at birth and cyanosis at the age of 6 years. His exercise tolerance was always limited. Examination at the age of 20 disclosed a systolic ejection murmur over the cardiac base and severe clubbing. The haematocrit was 87 per cent. Chest $x$-ray film disclosed the heart and pulmonary vessels to be of normal size, and the electrocardiogram showed right ventricular hypertrophy and a PR interval of 0.28 second. The pressure in the pulmonary artery was Received for publication 9 October 1978
$20 / 10 \mathrm{mmHg}$; in the right ventricle, $172 / 18 \mathrm{mmHg}$; and in the radial artery, $112 / 86 \mathrm{mmHg}$. The systemic arterial oxygen saturation was 63 per cent. A left subclavian-to-left pulmonary arterial anastomosis was performed when the patient was 20 years old in 1950.

Thereafter he did well until the age of 28 when exertional dyspnoea returned and it progressively worsened. When admitted to the National Heart Institute in March 1963, severe dyspnoea occurred when walking about 10 paces. A grade $3 / 6$ systolic ejection murmur was audible over the entire praecordium, loudest in the right parasternal second intercostal space. The blood haematocrit was 81 per cent. The electrocardiogram (Fig. 1) showed right axis deviation, bilateral enlargement, right ventricular hypertrophy with strain, and a prolonged ( 0.28 second) PR interval. At catheterisation, the pulmonary valve could not be traversed by the catheter. The right ventricular pressure was $105 / 10 \mathrm{mmHg}$ and the right atrial mean pressure was 8 , a wave 13 , and $v$ wave $9 \mathrm{mmHg}$. Simultaneous left ventricular and brachial arterial pressures were $142 / 13$ and $85 / 70 \mathrm{mmHg}$, respectively. The arterial oxygen saturation was 81 per cent. Cardiogreen dye curves showed a large rightto-left and a smaller left-to-right shunt at the atrial level. Left ventricular angiocardiogram showed a thickened aortic valve with a central jet. The heart 


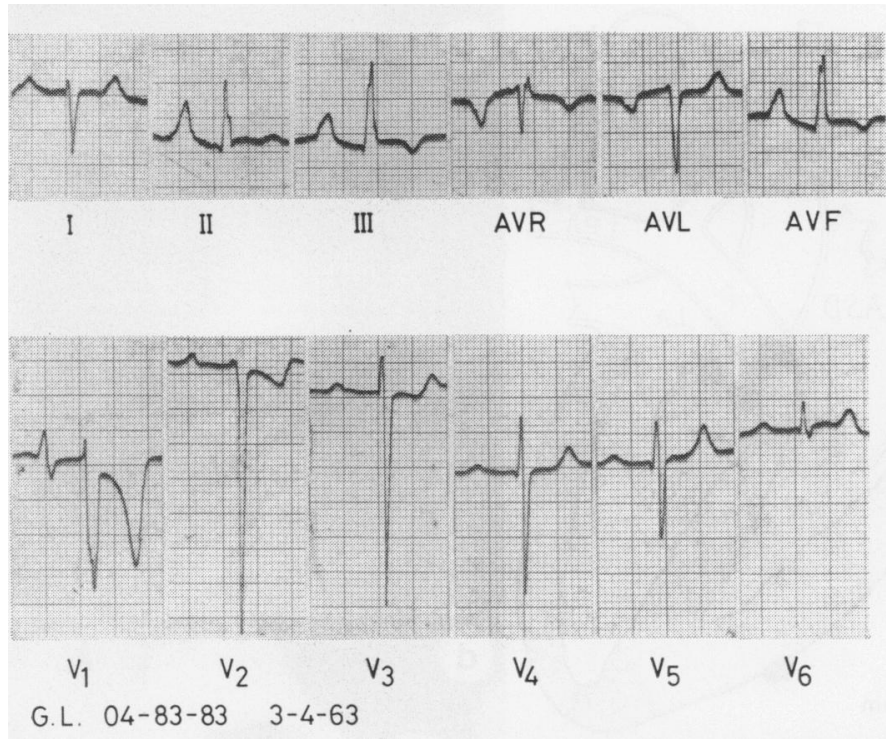

Fig. 1 Case 1. Electrocardiogram. Note the striking inversion of the $T$ wave in $V 1$, the prominent $P$ waves, prolonged $P R$ interval, evidence of right ventricular hypertrophy, and slight widening of the $Q R S$ complexes.

on chest $x$-ray film was slightly enlarged (Fig. 2), the aorta was elongated and dilated, and the pulmonary vessels were less prominent than normal.

At operation in March 1963, the pericardial space was obliterated by fibrous adhesions and foci of calcific deposits. Numerous collateral vessels were present in the mediastinum and pleura. A thrill was palpated in the ascending aorta. The pulmonary valve was heavily calcified and devoid of an orifice. Portions of the pulmonary valve and of the crista supraventricularis were excised. The large atrial septal defect (Fig. 2) was closed by a Teflon patch containing two perforations $0.6 \mathrm{~cm}$ in size. After coming off cardiopulmonary bypass, the pressure in the pulmonary trunk was $15 / 7 \mathrm{mmHg}$ and in the right ventricle $35 / 7 \mathrm{mmHg}$. Simultaneous left ventricular and brachial arterial pressures were $125 / 15$ and $75 / 40 \mathrm{mmHg}$, respectively. No procedure was carried out on the stenotic aortic valve. On return to the recovery room, he was hypotensive, despite vasopressors, and died 12 hours later.

At necropsy, $1200 \mathrm{ml}$ blood was present in the pleural spaces. The heart weighed $450 \mathrm{~g}$, the old pulmonary-subclavian arterial shunt was widely patent, the atrial septal patch was intact, and the right ventricular outflow tract and pulmonary valve appeared to be adequately opened (Fig. 2). The aortic valve was three-cuspid, calcified, and stenotic (Fig. 2). The left pulmonary arteries and veins were dilated, whereas those in the right lung had mildly thickened walls.

\section{CASE 2}

A 51-year-old white woman had a praecordial murmur at birth. Though always limiting her activities, she was asymptomatic until the age of 50 in 1976 when exertional dyspnoea, easy fatiguability, and pedal oedema were noted. In May 1977, cardiac catheterisation disclosed the following pressures: pulmonary artery, $26 / 17 \mathrm{mmHg}$; right ventricle, $128 / 20 \mathrm{mmHg}$; simultaneous left ventricle and aorta, $225 / 26$ and $110 / 70 \mathrm{mmHg}$, respectively; right atrium, mean 11 with a wave $21 \mathrm{mmHg}$. A left-to-right shunt of 1.2 to 1 was present at the atrial level.

Examination at the National Heart, Lung, and Blood Institute in November 1977 disclosed fixed splitting of the second heart sound at the cardiac base, a fourth heart sound, and a grade $3 / 6$ holosystolic murmur over the entire praecordium, loudest along the left sternal border. There was mild pedal oedema. The blood haematocrit was 43 per cent. The electrocardiogram (Fig. 3) showed biventricular hypertrophy, atrial abnormality, and indeterminate axis. Chest radiograph (Fig. 3) showed mild enlargement of the cardiac silhouette, dilatation of the ascending aorta, and calcific deposits in the aortic valve. The aortic valve was congenitally bicuspid (Fig. 4) and heavily calcified; it was excised and replaced with a Björk-Shiley prosthesis (size no. 19). The pulmonary valve was dome shaped, had a small central orifice, and was free of gross calcific deposits (Fig. 4). The atrial septal defect consisted of multiple openings in the 
Fig. 2 Case 1. (a) Diagram of heart showing total obstruction of the pulmonary valve and narrowing of the aortic valve. The pulmonary valve had been stenotic but not totally obstructed before the left subclavian ( $L S$ ) to left pulmonary arterial (LPA) anastomosis 13 years before death. $A S D$, atrial septal defect; $R A$, right atrium; $R V$, right ventricle; $P T$, pulmonary trunk; $I V C$, inferior vena cava; $S V C$, superior vena cava; $L A$, left atrium and $L V$, left ventricle. (b) Chest $\mathrm{x}$-ray film showing elongation of the aorta. (c) Opened left side of the heart showing a large secundum type atrial septal defect. (d) View of pulmonary $(P)$ and aortic $(A)$ valves from above. The pulmonary one had been opened at operation. $R$, right and $L$, left coronary arteries.

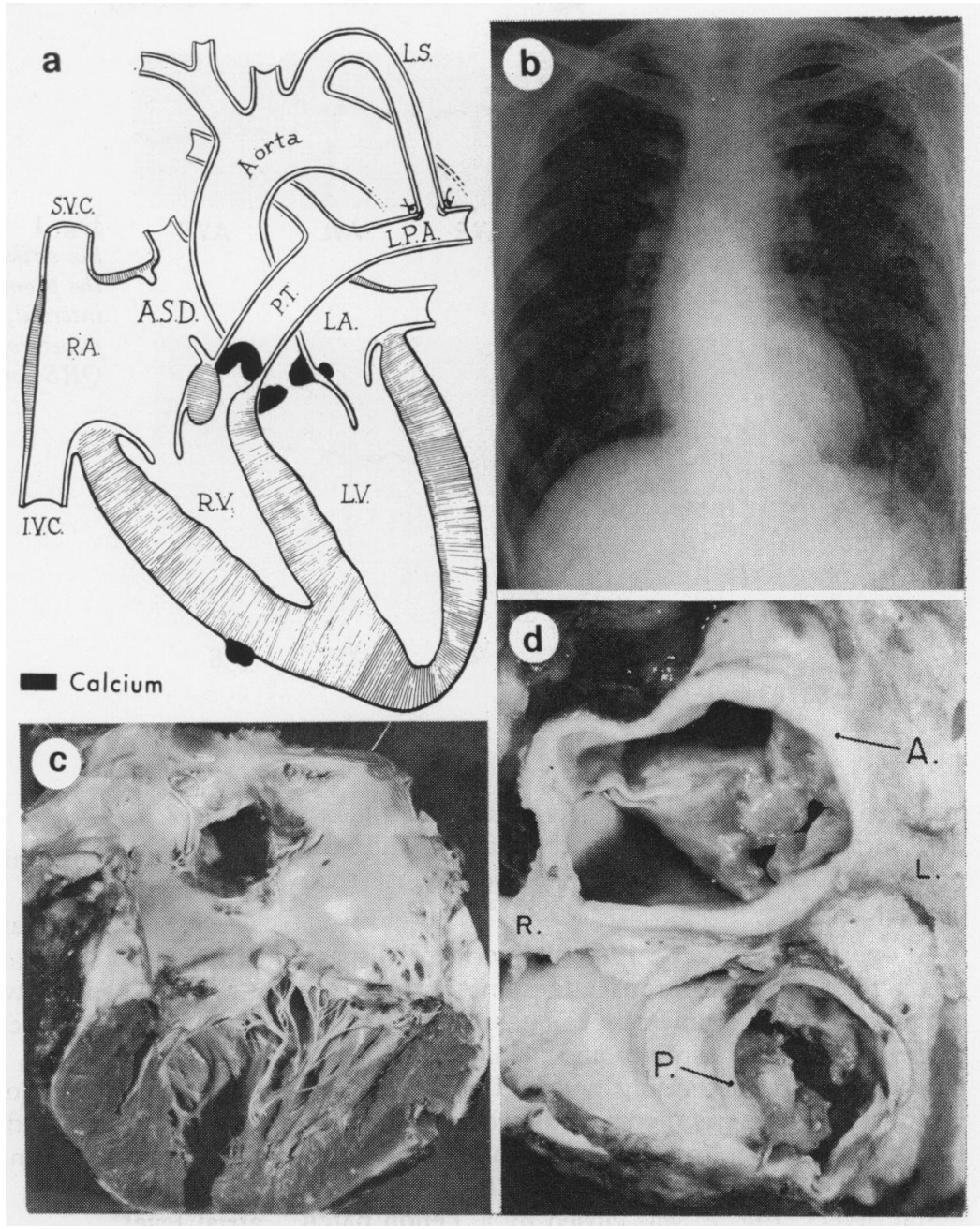

peripheral portions of the fossa ovale membrane and they were closed by multiple sutures. The largest of the openings was $1.0 \mathrm{~cm}$ in largest diameter. Measurements of pressures after discontinuation of cardiopulmonary bypass showed a $7 \mathrm{mmHg}$ peak systolic pressure gradient between right ventricular body and pulmonary trunk and no peak systolic pressure gradient between left ventricle and aorta. Her postoperative course was uneventful.

When seen 6 months after operation, she was asymptomatic. Repeat cardiac catheterisation disclosed the following pressures: pulmonary artery wedge mean, $12 \mathrm{mmHg}$; pulmonary artery, $34 /$ $11 \mathrm{mmHg}$; right ventricle, $38 / 12 \mathrm{mmHg}$; right atrial mean, $9 \mathrm{mmHg}$; and simultaneous left ventricle and aorta $160 / 20,152 / 78 \mathrm{mmHg}$, respectively. The cardiac index was $2.01 / \mathrm{min}$ per $\mathrm{m}^{2}$. No shunt was detected by dye curves.

\section{Comments}

The 2 patients described above were adults (33 and 51 years old), both had had praecordial murmurs from birth, both had severe valvular pulmonary stenosis (152 and $102 \mathrm{mmHg}$ gradients), both had considerable valvular aortic stenosis (57 and 115 $\mathrm{mmHg}$ gradients), and both had defects in the atrial septum. In case 1 , the gradient across the pulmonary valve before operation was nearly 3 times that of the gradient across the aortic valve (152 compared with $57 \mathrm{mmHg}$ ) and, consequently, the direction of the shunt across the large atrial septal defect was mainly right to left. In contrast, in case 2 , the gradient across the pulmonary valve was slightly less than that across the aortic valve (102 compared to $115 \mathrm{mmHg}$ ) and, consequently, the shunt across the atrial septal defect, though small, nevertheless, was entirely left to right. 


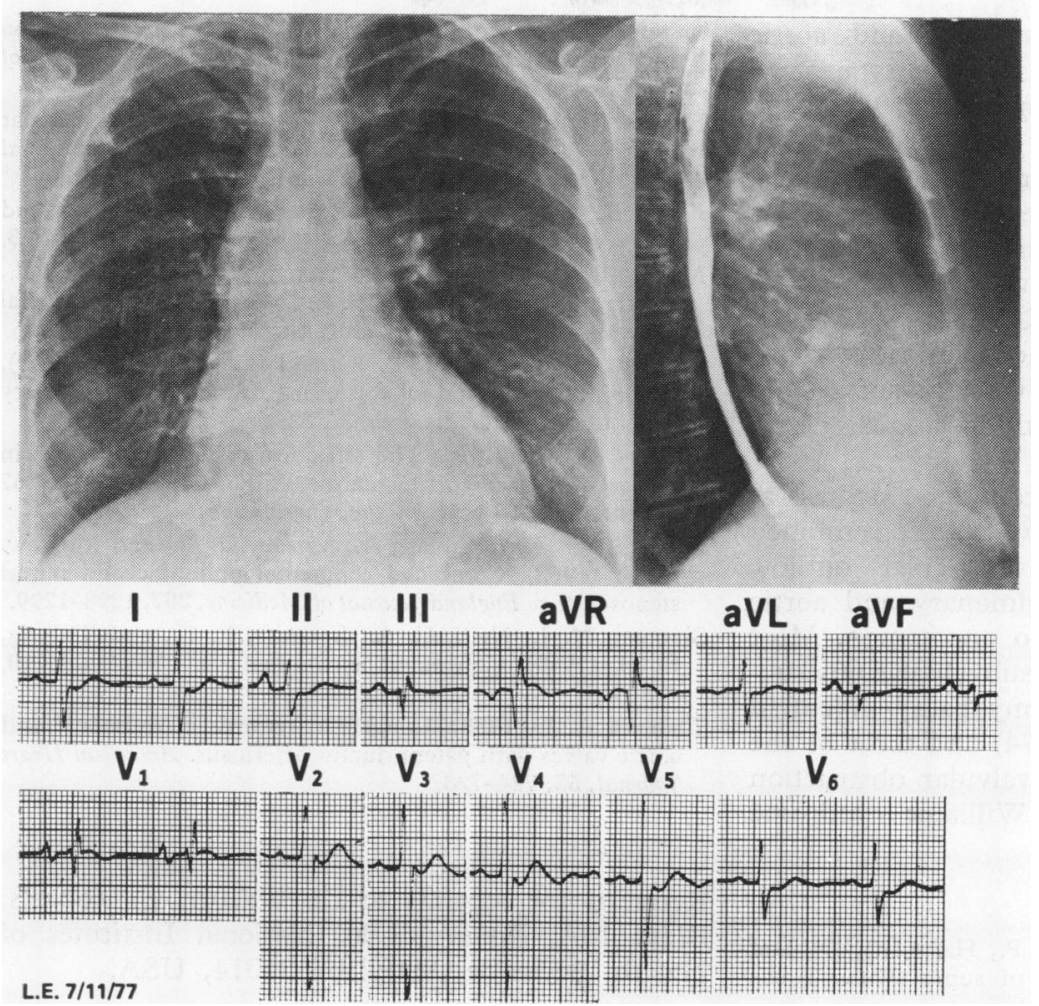

Fig. 3 Case 2. Chest x-ray film (above) and electrocardiogram (below) each taken a month before cardiac operation. On the lateral view, calcium deposits are discernible in the area of the aortic valve. The electrocardiogram shows biventricular hypertrophy, abnormal $P$ waves, and indeterminate axis.

When obstructive lesions are present on both sides of the heart, it is essential that both be recognised preoperatively and treated appropriately because relief of the right-sided obstruction without relief of the left-sided obstruction may cause fatal pulmonary congestion (Roberts et al., 1962). In our case 1 , the pulmonary valve stenosis was relieved and the atrial septal defect was closed but the aortic stenosis ( $57 \mathrm{mmHg}$ gradient) was not relieved.

Diagnosis of a left-sided cardiac obstructive lesion in the presence of right-sided obstruction may be difficult. Though present in both patients, dilatation and elongation of the ascending aorta on chest $x$-ray film was the only clinical clue in our case 1 suggesting an obstruction at the aortic valve level. The electrocardiogram in this patient did not show prominence of the left ventricular forces. Diagnosis of the associated aortic stenosis was suspected first at catheterisation after the catheter had crossed the atrial septal defect and entered the left ventricle which had a very high systolic pressure. Diagnosis of an associated left-sided obstructive lesion was more easily recognised in case 2 who had similar degrees of right and left ventricular outflow obstruction, rather than predominant right- sided obstruction as occurred in our case 1 . The electrocardiogram in case 2 consequently showed left as well as right ventricular hypertrophy and, in addition, calcific deposits were observed in the aortic valve area by chest $x$-ray film.

Surprisingly, few reports of combined valvular pulmonary and aortic stenosis with or without atrial septal defect have appeared. Horlick and Merriman (1957) described a 4-month-old boy

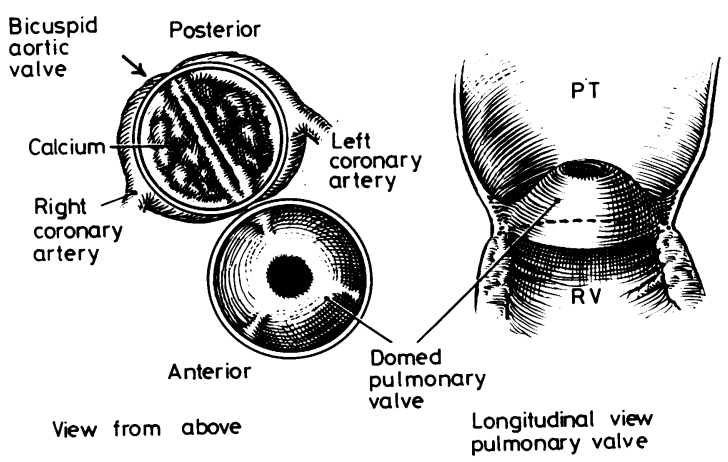

Fig. 4 Case 2. Diagram showing the stenotic pulmonary and aortic valves from above and the pulmonary valve on longitudinal view. 
with combined valvular pulmonary and aortic stenosis associated with a fossa ovale type atrial septal defect. Thomas (1958) described a 19-year-old man with valvular pulmonary and aortic stenosis associated with a small persistent ductus arteriosus. Sissman et al. (1959) described a 5-year-old boy with severe pulmonary stenosis and at operation associated valvular and subvalvular aortic stenosis was recognised. And, finally, Kelly (1965) reported a 28-year-old man with combined valvular pulmonary (60 $\mathrm{mmHg}$ gradient) and valvular aortic (110 $\mathrm{mmHg}$ gradient) stenosis without an associated shunt.

In contrast to the rarity of combined stenosis at the pulmonary and aortic valve levels, combined subvalvular right and left ventricular outflow obstruction and combined pulmonary and aortic supravalvular stenosis is not so uncommon. Most of the patients with combined subvalvular obstruction have hypertrophic cardiomyopathy (Neufeld et al., 1960; Maron et al., 1974) and most of the patients with combined supravalvular obstruction have the hypercalcaemic or Williams syndrome (Beuren et al., 1964).

\section{References}

Beuren, A. J., Schulze, C., Eberle, P., Harmjanz, D., and Apitz, J. (1964). The syndrome of supravalvular aortic stenosis, peripheral pulmonary stenosis, mental retardation and similar facial appearance. American fournal of Cardiology, 13, 471-483.

Horlick, L., and Merriman, J. E. (1957). Congenital valvular stenosis of pulmonary and aortic valves with atrial septal defect. American Heart fournal, 54, 615-620.

Kelly, D. J. (1965). Congenital stenosis of pulmonary and aortic valves. American fournal of Cardiology, 16, 750-753.

Maron, B. J., Edwards, J. E., Henry, W. L., Clark, C. E., Bingle, G. J., and Epstein, S. E. (1974). Asymmetric septal hypertrophy (ASH) in infancy. Circulation, 50, 809-820.

Neufeld, H. N., Ongley, P. A., and Edwards, J. E. (1960). Combined congenital subaortic and infundibular pulmonary stenosis. British Heart fournal, 22, 686-690.

Roberts, W. C. (1970). The structure of the aortic valve in clinically-isolated aortic stenosis. An autopsy study of 162 patients over 15 years of age. Circulation, 42, 91-97.

Roberts, W. C., Goldblatt, A., Mason, D. T., and Morrow, A. G. (1962). Combined congenital pulmonic and mitral stenosis. New England fournal of Medicine, 267, 1298-1299.

Sissman, N. J., Neill, C. A., Spencer, F. C., and Taussig, H. B. (1959). Congenital aortic stenosis. Circulation, 19, 458-468.

Thomas, A. J. (1958). Congenital stenosis of pulmonic and aortic valves with patent ductus arteriosus. American Heart fournal, 55, 724-728.

Requests for reprints to Dr William C. Roberts, Bldg. 10A, Room 3E-30, National Institutes of Health, Bethesda, Maryland 20014, USA. 